The Social Sciences 14 (11): 375-383, 2019

ISSN: $1818-5800$

(C) Medwell Journals, 2019

\title{
Sports Elementals and Value-Added Factors in Promotion of Football in Cross River State, Nigeria
}

\author{
${ }^{1}$ P.E. Ekuri and ${ }^{2}$ Michael A. Anndotan \\ ${ }^{1}$ Department of Human Kinetics and Health Education, University of Calabar, Calabar, Nigeria \\ ${ }^{2}$ Cross River State Sport Commission, Calabar, Nigeria
}

\begin{abstract}
The study investigated sports elementals and value-added factors in promotion of football in Cross River state, Nigeria. Survey research method of the ex-post-facto type was adopted for the study. The stratified random sampling technique was used to select $10 \%$ of football staff, board members of Cross River state football associations, organizing secretaries, coaches, assistant coaches and players of Cross River state for the study. Data collected were analyzed using one-way Analysis of Variance (ANOVA) at 0.05 level of significance and a post hoc analysis was further employed using Tukey Kramer multiple comparison test. The findings revealed that, funding has a significant relationship with the promotion of football $(\overline{\mathrm{X}}=21.00$; $\mathrm{SD}=2.04)$ and motivations of players has a significant relationship with the promotion of football in Cross River state $(\overline{\mathrm{X}}=21.65 ; \mathrm{SD}=4.24)$. The study recommended that state government should provide funds to support and promote football sports in the state, football coaches and football administrators should encourage players and gives them necessary motivation in terms of winning bonus, match bonus, goal scoring allowance, training allowance, medical welfare, etc.
\end{abstract}

Key words: Funding of football, motivation of football players, football promotion, Cross River state, Nigeria, winning bonus

\section{INTRODUCTION}

Football as a sport among other sports are people's choice. People have different reasons for choosing football as their favourite sport. Among these reasons are for entertainments, leisure, socialization, learning skills, personal training, etc. As a result people began to associate and are a supporter (fans) of a particular club. In light of this, in the word of Andrews and Harrington (2016) sports bind people together in local communities and over national boundaries. People across the world play sports and identify with sports teams and events, looking to these for a sense of identity, deep purpose and passing entertainment. Primarily because of this entertainment value, money has become a big part of many sports in recent years. A range of games have professionalized in the last few decades as a result and become active economic as well as social sectors. These include American sports, football (soccer), cricket, rugby (of different types), motor racing, boxing, athletics, swimming and more. Describe football as a sport with some characteristics that make it very attractive for both public and players. It is due to fact that it unites a series of simple movements that provoke emotions in the agents involved in the sport.

Funding of football add more value to football activities worldwide. Funding serves as incentive and for promotion of football in Cross River state. More, so, to maintain a facility funding is a necessity. Initially, an invested sum is set aside for the construction of a facility but afterwards there also needs to be an adequate allocation of funding to continue the facility's upkeep. Funding has to do with effective management of football and building the emotional and physical strength of participants. Fasan (2000) stated that sports management can be defined as activities which are intended towards the development of sports and is generally carried out by specific people trained in the management of sports. He asserted that the success of any sports programme depends to a large extent on the personnel available to administer it. He stressed further that to achieve this success, sports need capable, dedicated, efficient and qualified individual, so that, the aim and objectives could be achieved. Funding is also essential in the area of equipment that will facilitate effective sports performance of the players. Due to the essentiality of funding in football, the sports industry provides a platform for sports-related businesses to generate profits through sports retail and manufacturing, media and hospitality, venues and infrastructure as well as merchandising (Bing et al., 2015; KPMG., 2014) in Llewellyn. As such the business of sport has become a critical engine of economic growth, providing job opportunities, stimulating investment and developing consumer consumption through its spectators (De Burca et al., 2015; Smith and Stewart, 2007). More, so, motivation strategy is another

Corresponding Author: P.E. Ekuri, Department of Human Kinetics and Health Education, University of Calabar, Calabar, Nigeria 
value-added factor in the promotion of football. Funding alone without motivation that could serves as incentives to the coaches, administrators and players could be said to be floating if appropriate incentives are not in place.

Motivation is one of the most analysed factors in sports psychology as it is one of the most influential factors in explaining human behavior. Sees motivation in football as a crucial aspect in sport and that motivation directly influencing behaviour, changing its intensity, direction and attitude. The most exciting moment that football staff and players of Cross River state could have is when they are giving motivation. Motivation could be in divers form such as weekly motivation, winning bonus, match bonus, goal scoring allowance, training allowance, medical welfare, advertisement bonus, kits allowance, trophy allowance, contract allowance and vacation trip. It has been unanimously agreed that the coach's main mission is to develop the technical and tactical skills of footballers (Castro-Sanchez et al., 2018). In the last two decades, psychological factors have gained special relevance in sports field. The latter having a close relationship with sports performance as in the case of motivation. Therefore, agrees that coaches are the ones who create motivational climates in their teams they will promote orientations of their players towards task or towards ego.

Lack of adequate funding and motivation strategies serve as challenges not only on the part of players and coaches but on the part of administration. A good administrative sense and training is necessary for effective utilization of resources available for football organization. These resources according to Ehiametalor include fund, facilities, equipment, men and medical services. It is in the light of this that this study was conceived to find out the sports elementals and value-added factors in promotion of football in Cross River state, Nigeria.

Statement of the problem: Football in Nigeria, Cross River state inclusive had performed better in the National Pro-League 1 and National Premier League amongst the 36 states of the federation before the year 2000. However, the state showed a poor performance in 2000 when it was placed 10th position on the National Division one football table. In 2002/2003, the state football club reduced drastically by going down to National Division 2 with 18 th position in the football season table. As a result of low performance the team could not gain promotion to National Premier League due to several challenges among which are inadequate funding and poor motivation of football players which drastically affect the promotion of football in Cross River state.

Research questions: The following research questions were drawn to guide the study:
- How does funding of football influence the promotion of football in Cross River state?

- To what extent does motivation of players influence the promotion of football in Cross River state?

Hypothesis: The hypothesis formulated for the study are listed below and were tested at 0.05 level of significance:

- Funding of football has a significant influence on the promotion of football in Cross River state

- There is no significant influence of motivation of players on the promotion of football in Cross River state

Funding and promotion of football: For an organization to be successful, it need resources to be able to carry out her football programmes effectively. The Oxford Advanced Learner's Dictionary defines funding as a means of providing funds or money for what one intends to do or provision of money for an activity or programme. As reported by Ataha (2007) studied adequate finance for effective sport performance. In his research, 250 subjects were used. It was established that a greater percentage (93\%) of the subjects agreed to the fact that to achieve effective sports performance, enough money should be budgeted. The remaining percentage $(5 \%)$ did not see with insufficient finance having anything with effective sports performance and development.

Ehiametalor said that money is perhaps one of the greatest limiting factors in the maintenance of sport building, equipment's and organization of football activities. Usually little attention is paid to infrastructural maintenance in the federal, state and local governments budgets. Instead, emphasis is usually on new sport facilities and equipment while the old ones that need refurbishing are abandoned. Salami (1999), added that funds comes in different forms and different types. Sports offer commensurable salaries and bounces for service rendered by players. In football, most favourable incentives come in monetary form. This is made up of the salaries and wages, sign-on-fees, match winning bonuses and other allowances.

The Nigeria government has been identified as being major proprietor of football in terms of funding and administration (Abone, 2003; Amuchie, 2003; FRN. (Federal Republic of Nigeria), 2000). The includes the obligations of the three tiers of government (Federal, State and Local Government) amongst others to be providing enabling legislation for football, formulation and review of the national sports policy, development and maintenance of football, ensuring adequate budgetary allocations for sports, organizing and funding of researches in football as well as ensuring that at least 5\% of the total budget for sports is earmarked for maintenance of sports facilities and infrastructure. 
Unokan (2005), added that for anything to be done requires financial budgeting. Football organization or management is capital intensive. He noted that adequate finance is of great importance in football organization owing to the fact that an enormous amount of money is required to put, so, many things in place. He stated that football competition and players need funding to survive. In effect, funding in football is of material and human resources. In support to this assertion, National Sports blue print by Ndanusa (2010) foreseen the administration of sports as to achieve success and that it requires cost effectiveness and cost benefit analysis of what is needed in the programme. Therefore, according to Orunaboka and Ogulu (2015) it is however, expected that the state government and local governments will collaborate to jointly finance the construction of the community sports centres and develop a sports programmes in the face of the competing demands for financial resources.

Material funding involve the preparation of football pitch, procurement of facilities and equipment needed for the sports, payment to the media houses that will cover events and many other exigencies on the part of the organizing officials. While the term managers or football administrators will need to provide kids, pay for training or camping venues and feed the crew while in camp. Human funding talks about payment of allowances or competition bonuses, hospital bills and other motivational packages to boost optimum performance, players struggles for positions in a well-remunerated club side. This is why most Nigeria stars travel to advanced countries to serve in clubs over there. This is also the reason why cooperate bodies, companies and able individuals give bonuses to well performed players and clubs in the state (Unokan, 2005).

No football programme can be administered successfully without adequate funding. Ogunjimi (2005) stated that the provision of adequate funds is a key to success in sports. He went on to explained that no matter the amount of well-planned laid out programme strategies by coaches and football administrators, inadequate supply of funds for such noble plans will spell down for the success of such programme. Mkav (2013) viewed that funding and implementation of budget constitutes success in any sports programme and therefore, must be made available at all the time. In fact, this as certain agrees with Erico (2010) who observes as true of our national teams where there will be no proper preparation in term of training, camping of the athletes and organizing friendly matches to assess the level of preparedness, late camping of athletes and in fact, not exposing athletes and coaches to the outside world to be abreast with the world best practices is the order of the day because of lack of fund.

Ezeocha (2005), pointed out that only a financially, viable organization can function well and that it is quite an uphill task to operate any system without adequate finance because this can result in frustration on the job. Asserted that the growing complexity in terms of population, resources, organization and management for more result oriented activities in sports attracts huge financial investment, for example among other things requires money. In line with the above assertion, the researcher opines that it is therefore, imperative for each football club to have a budgetary plan strictly for football. It will help to streamline monies for football programmes and proper accountability.

Motivation and promotion of football: Motivation is the tendency for the direction and selectivity of behaviour to be controlled by its connection to consequences and the tendency of this behaviour to persist unit a goal is achieved. Motivation therefore, according to Mkav (2013) is one of the most important factors in learning without it there can be no learning. Incentives motivate players into higher performance. When good incentive is given, the possibility is for the athlete to seek to perform better for his reward. Motivation is a vital prerequisite to learning and performance. This great concern prompted Siasia (2011) said "the failure of clubs management to make our league more attractive is making some Nigerian players to run to Europe because of money, one cannot expect players to prosecute matches in the league if they are not paid well. He made it clear that, coache's cannot go into the field to play football. They need to be financially assisted by the club management to get the best leagues results for their club side". Ikhioya (2001), added that the persistence of an individual partaking in any act is influenced by possibilities of achieving ambitions or felt needs. According to Nevid (2012) cited in Ajowi (2016) motivation is considered to be the most important among the psychological factors that affect sporting success because it stimulates an individual's behavior towards a certain direction. It represents the forces that introduce an athlete to a skill or an activity, direct and sustain their behavior. Deci and Ryan (2002), reported that individuals are motivated depending on the difference in their perceived competence and self-determination.

According to Ajowi (2016) motivation is a psychological trait that has important implications on football participation and is most times overlooked in the development and cultivation of skill for elite football players. Within a sports context, individual player's motives toward participation may be influenced by a variety of socio-psychological and physiological agents. In the context of football, motivation is one of the concepts most referred to amongst the reasons that justify the success and very often, the failure of players and of teams. Frequently coaches, players and audience associate the collective and individual performance to different motivational states. The study by Castro-Sanchez et al. 
(2018) maintained that motivational climate promoted by a football coach is directly related to the player's perception of their performance on the pitch. Also determines the degree of commitment and fun of the players (Duda and Balaguer, 2007). A study by Garcia-Calvo found that players with a task-oriented climate were more committed to playing sports.

The two distinct types of motivation which has been identified by various researchers in education are intrinsic and extrinsic motivation. Intrinsic motivation is originated from within a player that is to say that a player engages in an activity because of an innate urge to participate in such activity mainly because it provide pure enjoyment or satisfaction for him or her. In view of this, winning or losing a match does not matter to the player and therefore, no reward is expected from any player or organization because he/she did not achieve the goal set. Defined the intrinsic motivation as it is triggered by personal desires and attentions without having external effects or reassons. While extrinsic motivation occurs when an individual or player participates in an activity such as training, football competition, purely for the external reward, either in form of prize money or material gift attached to it successful completion. The monetary or material gifts or other promise may be the major drive in assisting the player to put in all his efforts to ensure that he achieves a good result. As an administrator of a football club, you should put player's equipment in good order, to achieve their goals. According to Ozgider (2016) individuals do not change their behavior even if they are forced to do that. However, the only way that they might change their behavior is motives coming from outside. Indicated that the reward determines which behavior you want or not. In other words if you give reward to an individual's desired behavior, he/she will show that behavior again.

However, it is believed that both types of motivation influence player's behaviour in football setting but it has been discovered that a player will measure up perform better when there is extrinsic motivation attached. This can be observed in two clubs A and B, football club A which has all facilities and equipment will perform better in football tournament than club B who has few or no facilities, players, football administrators and other football officials need to be encouraged by means of receiving rewards either positively or negatively. By, so, doing, greater involvement, participation and performance could be achieved. According to Bernard and Buss cited by Mkav (2013) sports programme in developing countries (Nigeria) are usually run by sports coaches who work on a voluntary basis but sports projects have shown to require specialized and trained staff in order to reach the desired outcomes. As such in order to get capable people to become actively involved in girls and women's sport, incentives must be provided such as remuneration, transferable skills, equipment and further education (training) media exposure, travel opportunities or other resources) to make the programme sustainable. Lee reported the result of an investigation of concerns related to youth sports and motivation of young players in competitive football. The study was conducted at the 1998 Moscow Youth Games. Results of study indicated that interest was the greatest motivation factor for continuing sport participation by young players. It was also found that government support was lacking for youth in terms of the education system and finances. The study further revealed that policy changes in the education system to facilitate player needs were not met. It is identified that intrinsic motivation of young players did not take priority over extrinsic values in organizing youth football.

According to Taylor and Taylor (2007), defined motivation as the ability to initiate and persist at a task, being able to offer sustained effort in the face of competing obstacles including pain, fatigue, boredom, frustration, set backs and the desire to do other less unpleasant activities. Motivation they said is essential to participation and performance because it is the only factor that players can control and the utilization of that control directly influence the quality and duration of participation and performance in football. Nwaoku (2005) agreed with this assertion that motivation plays an important role during the entire process of acquisition of skills and mastery of physical skills is essential to success (performance) in sports. Without motivation, optimum performance cannot ensue in fact there might be no interest whatsoever to drive player to train effectively during training sessions and real competition.

Ali and Ahmed (2009), reported in their study that there is a statistically significant relationship between reward and recognition, motivation and performance, respectively and that if reward or recognition offered to employee were to be altered then there would be a corresponding change in work motivation. Salami (1999), stated that staff training and development would not only enhance skills of the workers but could also make them realize who they are valued by organization.

Henman (2007), admitted that if properly used, player's motivation could become a vital tool to get the best out of players. He emphasized further the impact of using different methods such as speaking positive words to applaud a good job, exercising restraint, patience and understanding of players as morale booster with a view of getting the best out of them. He added that the categories of motivating people to work include:

- Intrinsic motivation which are growth oriented factors

- Extrinsic motivation factor which re peripherally related to the job

Emu (2003), carried out a research on ways of 
motivating footballers to achieve optimum performance. In his research, two sets of footballers were monitored. Half of the population $(n=25)$ was kept in a closed camped with different incentives given while the other half $(n=25)$ was not given incentives. Towards the end of the experiment, both groups $(\mathrm{n}=50)$ were brought together, competition was organized. The group that was in a close camp performed better than the other group that was not motivated.

The influence of motivation on players is enormous. Motivated players, under normal conditions would be happy, joyous and at the same time performed highly. This is because when the player is happy, he will be willing to give the best to his club. In other words, a motivated player does not need to be forced to his normal duties but will rather be willing to discharge his duties joyfully, optimally and efficiently. Motivated players would be willing to do everything possible to optimize his performance, since, this has direct bearing on the total football performance.

Theoretical framework: This study is based on the following theories that are related to the variables in the study. The principles of scientific management theory by Frederick Winslow Taylor in 1911. Administrative theory by Henri Fayol in 1949.

The principles of scientific management theory: This is a management theory founded by Frederick Taylor in 1911. The term scientific management has no precise definition but could be conceived as that art and science of managing "man" and "work" in the work place. Taylor spent the greater part of his life working on the problem methods. He realized that the key to such problems lay in the systematic analysis of work. Experience, both as a worker and as a manager had convinced him that few if any workers put more than the minimal effort into daily work. He described this tendency as "soldiering" which he subdivided into "natural" "soldering", i.e., man's natural tendency to take things easy and systematic "soldering".

The efficiency concept comes from his concern for adoption of principles of work and motion study. Taylor believed that each piece of work should be properly planned or articulated, so as, to increase works efficiency in the use of the relevant tools. The motion study is concerned with training each worker on the relevant techniques and methodologies for carrying out any piece of work.

Finally, Taylor advocated good reward system for workers as means for motivating them for enhanced productivity. To this end, he looks at every worker as an economic man or machine model that has to work with break-stop until the assigned task is accomplished. The reward system includes salaries increment, bonuses, award of prizes for distinguished worker of the period considered. Some aspects of Taylor's efficiency for systematic training of all workers are ideal for football administrators in football organization. Although, all coaches and football administrators are expected to be professionally trained before their initial appointments an induction course should be arranged for newly recruited staff as a kind of orientation exercise to enable them to easily adapt themselves to practical realities of their dreams in their profession. This is capable of giving them the initial motivation to appreciate the worth and demand of job itself.

Taylor's strict supervision with time measurement was highly compensated with appropriate reward system. This is why prizes or awards that could be offered to deserving coaches, administrators and players may not necessarily be in monetary terms but in professional excellence state government award as recognition for some outstanding strategies of Taylor's may yield positive results that are proofs of the administrative supervision and effectiveness of the head of football organization. On the other hand, scientific management reduced the workers role to that of right adherence to methods and procedures over which he had no discretion. It led to the fragmentation of work on account of its emphasis on the analysis and organization of individual tasks.

Administrative theory: Administrative effectiveness can only be experienced through the application of an administrative theory which is the pioneering work of Henri Fayol in 1949. Fayol had his inspiration for effective administration earlier as a French Air-Force officer and as he joined the industry on retirement, he developed his military administrative theory popularly known as "universal or general principles of administration". Henri Fayol, a French Geologist, engineer and industrialist was one of the first industrial scientists that maintained that administration can be taught and learned.

Fayol's initial intention was to identify five functions of administration which are planning, organizing, controlling, coordinating and commanding. These functions he experienced as follows.

Planning: Projecting activities or programme for the future in other words, the process of studying the future and arranging the plan of action towards achieving the goals of the organization. It also involves selection from among alternatives, future courses of action for an organization.

Organizing: Arranging materials and human resources of organization for effective utilization. In other words, accumulation of material and human resources needed for successful performance of the task. 
Controlling: This is the act of ensuring that all things are done according to set standards. It entails ensuring that everything is done in accordance with the established rules and regulations.

Coordinating: This involves monitoring work processes to ensure that all things are put together to achieve successful performance of the task.

Staffing: Staffing incorporates the personnel function of recruitment, selection, placement, training, promotion, discipline and warfare.

Decision making: This involve the activities and processes of analyzing and synthesizing ideas and opinions as means of finding solution to problems.

\section{MATERIALS AND METHODS}

The research design adopted for this study was descriptive survey research which includes the causal-comparative (Ex-post-Facto) method of research. The respondents were football staff, board members of Cross River state football associations, organizing secretaries, coaches, assistant coaches and players of Cross River state. The study population was determined using $10 \%$ of the whole Cross River state football board members, coaches, football administrators and players of the Cross River state using stratified random sampling technique. A total of 150 questionnaires were distributed, returned and found valid for data analysis. The research instrument was a self-developed scale. The reliability coefficient for funding of football was found to be 0.72 and motivation of football players was found to be 0.70 using Cronbach-alpha method.

\section{RESULTS AND DISCUSSION}

$\mathbf{H}_{\mathbf{1}}$ : There is no significant influence of funding on promotion of football in Cross River state.

The independent variable in this hypothesis is funding (low, moderate and high) while the dependent variable is promotion of football. To test this hypothesis, promotion of football from funding low, moderate and high were compared using one-way Analysis of Variance (ANOVA). The result of the analysis is presented in Table 1 and 2.

The result on Table 1 and 2 revealed that the calculated F-value of 15.393 is higher than the critical F-value of 3.00 at 0.05 level of significance with 2 and $147^{\circ}$ of freedom. With this result the null hypothesis which stated that funding has no significant influence on promotion of football was rejected. This result, therefore, implies that funding significantly influence promotion of football. Since, funding has a
Table 1: Summary data and one-way ANOVA of the influence of funding on promotion of football $(\mathrm{N}=150)$

\begin{tabular}{lllr}
\hline Funding & $\mathrm{N}$ & $\overline{\mathrm{X}}$ & $\mathrm{SD}$ \\
\hline Low -1 & 50 & 22.80 & 1.18 \\
Moderate -2 & 60 & 22.50 & 0.77 \\
High -3 & 40 & 21.00 & 2.04 \\
\hline
\end{tabular}

Table 2: Summary data and one-way ANOVA of the influence of funding on promotion of football $(\mathrm{N}=150)$ : ANOVA tables

\begin{tabular}{lccc}
\hline Source of variation & $\begin{array}{c}\text { Degrees of } \\
\text { freedom }\end{array}$ & $\begin{array}{c}\text { Sum of } \\
\text { squares }\end{array}$ & $\begin{array}{c}\text { Mean } \\
\text { square }\end{array}$ \\
\hline Treatments (between columns) & 2 & 391.61 & 195.80 \\
Residuals (within columns) & 147 & 1869.8 & 12.720 \\
Total & 149 & 2261.5 & \\
\hline
\end{tabular}

$\mathrm{F}=15.393=(\mathrm{MS}$ treatment/MS residual $), *$ Significant at 0.05 level, Critical $\mathrm{F}=3.00, \mathrm{df}=2,147$

Table 3: Tukey-Kramer multiple comparison analysis of the influence of funding on promotion of football, if the value of $q$ is $>3.353$ then the is $<0.05$

\begin{tabular}{lclll}
\hline Comparison & Mean difference & \multicolumn{2}{c}{$\mathrm{q}$} & $\mathrm{p}$-values \\
\hline Low vs Moderate & -3.110 & 5.529 & $* *$ & $\mathrm{p}<0.001$ \\
Low vs High & -3.990 & 7.765 & $* * *$ & $\mathrm{p}<0.001$ \\
Moderate vs High & -0.8800 & 1.809 & $\mathrm{~ns}$ & $\mathrm{p}>0.05$ \\
& Mean & $95 \%$ confidence interval \\
Difference & difference & From & To \\
Low-moderate & -3.110 & -4.996 & -1.224 \\
Low-high & -3.990 & -5.713 & & -2.267 \\
Moderate-high & -0.8800 & -2.511 & & 0.7514 \\
\hline
\end{tabular}

Table 4: Summary data and one-way ANOVA of the influence of motivation of player on promotion of football $(\mathrm{N}=150)$

\begin{tabular}{llcr}
\hline Motivation of players & $\mathrm{N}$ & $\overline{\mathrm{X}}$ & $\mathrm{SD}$ \\
\hline Low & 26 & 17.25 & 3.02 \\
Moderate & 48 & 19.43 & 3.43 \\
High & 76 & 21.65 & 4.24 \\
\hline
\end{tabular}

Table 5: Summary data and one-way ANOVA of the influence of motivation of player on promotion of football $(\mathrm{N}=150)$ : ANOVA table

\begin{tabular}{lcrr}
\hline $\begin{array}{l}\text { Source of } \\
\text { variation }\end{array}$ & $\begin{array}{c}\text { Degrees of } \\
\text { freedom }\end{array}$ & $\begin{array}{r}\text { Sum of } \\
\text { squares }\end{array}$ & $\begin{array}{r}\text { Mean } \\
\text { square }\end{array}$ \\
\hline Treatments (between columns) & 2 & 414.43 & 207.220 \\
Residuals (within columns) & 147 & 2129.30 & 14.485 \\
Total & 149 & 2543.70 & \\
\hline
\end{tabular}

$\overline{\mathrm{F}}=14.306=(\mathrm{MS}$ treatment/MS residual $), *$ Significant at 0.05 level, Critical $\mathrm{F}=3.00, \mathrm{df}=2,147$

significant influence on promotion of football, a post hoc analysis was employed using Tukey-Kramer multiple comparison analysis. The result of the analysis is presented in Table 3.

$\mathrm{H}_{2}$ : there is no significant influence of motivation of player on promotion of football in Cross River State: The independent variable in this hypothesis is motivation of player (low, moderate and high) while the dependent variable is promotion of football. To test this hypothesis, promotion of football from motivation of player low, moderate and high were compared using one-way Analysis of Variance (ANOVA). The result of the analysis is presented in Table 4 and 5 . 
The result on Table 4 and 5 revealed that the calculated F-value of 14.306 is higher than the critical F-value of 3.00 at 0.05 level of significance with 2 and $147^{\circ}$ of freedom. With this result the null hypothesis which stated that motivation of player has no significant influence on promotion of football was rejected. This result therefore implies that, motivation of player has a significant influence on promotion of football. Since, motivation of players has a significant influence on promotion of football, a post hoc analysis was employed using Tukey-Kramer multiple comparison analysis. The result of the analysis is presented in Table 6.

The result of the above post-hoc analysis showed q values of 3.327, 7.196 and 4.474 for low/moderate, low/high and moderate/high, respectively. The influence of low/moderate was not significant because the $\mathrm{q}$ value of 3.327 was $<3.353$ while there was significant influences of the other two groups compared because their q values were higher than 3.353 .

The study was designed to examine sports elementals and value-added factors in promotion of football in Cross River state, Nigeria. The findings arising from the results of the statistical analysis of the two hypotheses directing the study are presented on the following headings:

Funding and promotion of football: The result revealed that the calculated F-value of 12.859 is higher than the critical F-value of 3.00 at .05 level of significance with 2 and $147^{\circ}$ of freedom. This result therefore implies that funding significantly influence promotion of football. The finding is in agreement with the works by Akinsami Andrew and Harrington (2004) they all confirmed that inadequate funding is a bane of football programme in Nigeria.

Poor funding has been one of the major problems affecting players participation in games sports and recreational activities in the state. In a study carried out on challenges to female sports and participation, it was discovered that inadequate funds was a major barrier to female football promotion. Unokan (2005) who agreed fervently well with findings of this hypothesis five revealed that for anything done or be done requires financial budgeting. He noted that adequate finance is of great importance in football organization owing to the fact that an enormous amount of money is required to put, so, many things in place. He concluded that football competition and players need funding to survive.

Indeed, the importance of finance availability cannot be over-emphasized as asserted by various administrative researcher such as Ezeocho (2005), among several others. To Ezeocha (2005), only a financially viable organization can function well and that it is quite an uphill task to any system without adequate finance because this can result in frustration on the job.
Motivation of player and promotion of football: The statistical analysis of hypothesis two of this study has revealed the fact that there is a significant influence of motivation of players on the promotion of football. These exposition are highly in agreement with who Ndagaha in his study sees effective promotion of football and motivation as the opposite side of the same coin. To Ndagaha, a well performing worker is a motivated worker and vice versa, who is always happy and contented and see no disparity, once any disparities are observed the effective worker becomes discounted. These assertions are also agreed with Ali and Ahmed (2009) who in their study found a statistical significant relationship between reward and recognition and between motivation of player and promotion of football and that if reward of recognition offered to employees were to be altered, a corresponding change in work motivation and football promotion would be observed in a similar vein. In summary, this study also aligns very well with Etuk who recommended that certain workers in agencies who are assigned special functional duties in addition to their normal functional by their heads due to their proven integrities in various aspects of the administration, should be highly or appropriately motivated. This will surely create in such workers, players or football administration or secretaries and coaches a high sense of fulfillment and satisfaction.

Summary of major findings: This study focused on sports elementals and value-added factors in promotion of football in Cross River state, Nigeria. Two research questions and two hypothesis were formulated to guide the study. The research design adopted for the study was descriptive research of ex post facto type while the data was generated from 150 respondents from football administrators, board members, coaches, secretaries and players in the study area. The statistical instrument used was one-way Analysis of Variance (ANOVA). The data analysis revealed that there is a significant influence of funding on the promotion of football in Cross River State and motivation of players was significant related to the promotion of football in Cross River state.

\section{CONCLUSION}

Based on the findings of this study, the following conclusions were made. Funding has a significant relationship with the promotion of football and motivations of players were significant predictors of promotion of football in Cross River state. This is an undebated facts as studies has established that the provision of adequate funds is a key to success in sports (Ogunjimi, 2005). Also, according to Nevid (2012) cited by Ajowi (2016) motivation is considered to be the most important among the psychological factors that affect sporting success because it stimulates an individual's behavior towards a certain direction. 


\section{RECOMMENDATIONS}

In view of the conclusion stated or drawn above, the following recommendations are put forward: state government should provide funds to support and promote football sports in the state. This will enable growth and bring football in lime light and as well open room for participants.

Private organization should be allowed managing and funding football to improve and promote the game. More professional women should be encourage to be part of football clubs.

The football coaches and football administrators should encourage players and gives them necessary motivation in terms of winning bonus, match bonus, goal scoring allowance, training allowance, medical welfare, etc.

\section{ACKNOWLEDGEMENT}

The researcher wishes to thank the Almighty God for His guidance and direction during this research. Also, my unreserved thanks go to my immediate family (my lovely husband and children) for their understanding for the course of this research. Not to also forget the role of Mr. Ikegune Daniel who served as a research assistant.

\section{REFERENCES}

Abone, O.M., 2003. Marketing and sponsorship of sports in Nigerian schools. Anambra State J. Phys. Health Educ. Recreation Sport Dance (ANJOPHER.SD), 1: 95-104.

Ajowi, C.A., 2016. Participation motives and competitive orientation of football players in the Kenyan women premier league. M.Sc. Thesis, Kenyatta University, Nairobi, Kenya.

Ali, R. and M.S. Ahmed, 2009. The impact of reward and recognition programs on employee's motivation and satisfaction: An empirical study. Int. Rev. Bus. Res., 5: 270-279.

Amuchie, F.A., 2003. Pres-Colonial Sports in Nigeria: Their Influence on Contemporary Sports Development in Nigeria. In: Sports in Contemporary Africa Society: An Anthology, Amusa, L.O. and A.L. Toriola (Eds.). Dynasty Printers (Pty) Ltd, Mokopane, South Africa, pp: 47-64.

Andrews, M. and P. Harrington, 2016. Off pitch: Football's financial integrity weaknesses and how to strengthen them. HKS Working Paper No. RWP16-009, Harvard University, Cambridge, Massachusetts, USA. https://papers.ssrn. com/sol3/papers.cfm?abstract_id=2746644.
Ataha, G.C., 2007. Management indices of cross river state secondary schools student's participation and performance in national school sports programmes. M.Ed. Thesis, University of Calabar, Calabar, Nigeria.

Bing, Z., Y. Li, T. Miao, W. ZiWen, C. XueFeng, L. Lu and L. Feng, 2015. Sports industry and tourism integrative development effectiveness prediction. J. Chem. Pharm. Res., 7: 1867-1872.

Castro-Sanchez, M., F. Zurita-Ortega, J.L. UbagoJimenez, I.A. Ramirez-Granizo and R. ChaconCuberos, 2018. Motivational climate in youth football players. Behav. Sci., Vol. 8, No. 9. 10.3390/bs8090083

De Burca, S., T. Brannick and T. Meenaghan, 2015. Spectators as Consumers-the Motivating Forces. In: Proceedings of the 1993 World Marketing Congress, Sirgy, M.J., K.D. Bahn and T. Erem (Eds.). Springer, Cham, Switzerland, ISBN: 978-3-319-17322-1, pp: 644-648.

Deci, E.L. and R.M. Ryan, 2002. Overview of Self-Determination Theory: An Organismic Dialectical Perspective. In: Handbook of Self- Determination Research, Deci, E.L. and R.M. Ryan (Eds.). University of Rochester Press, Rochester, New York, USA., ISBN: 1-58046-156-5, pp: 3-33.

Duda, J.L. and I. Balaguer, 2007. Coach-Created Motivational Climate. In: Social Psychology in Sport, Jowet, S. and D. Lavallee (Eds.). Human Kinetics Publisher, Champaign, Illinois, USA., ISBN-13: 978-0-7360- 5780-6, pp: 117-130.

Emu, S.O., 2003. Techniques in motivating footballers to achieve optimal performance in Edo State. Master Thesis, University of Benin, Benin, Nigeria.

Erico, J., 2010. Attitudinal change by the player, administrators. Soccer Stars Limited, UK.

Ezeocha, P.A., 2005. School Management and Supervision. Owerri Executive Publishers, Owerri, Nigeria,.

FRN. (Federal Republic of Nigeria), 2000. National Sports Policy of Nigeria (Revised Draft Copy). Federal Republic of Nigeria Abuja, Nigeria.

Fasan, C.O., 2000. Introduction to Sports Administration. Beulah Publishers, Lagos, Nigeria,.

Henman, I., 2007. Staff motivation the key to a strong work environment. The Free Library, Philadelphia, Pennsylvania.

Ikhioya, O.S.A., 2001. Functional Strategies for Effective Sports Management Practices: Guides for Sports Managers and Administrators. Sports and Leisure Consult, Lagos, Nigeria,.

KPMG., 2014. Business of sports (adobe digital editions version). KPMG, Amstelveen, Netherlands.

Mkav, B.E., 2013. Perceived administrative tasks as determinants of job performance by indigenous football coaches in FCT, Abuja. Ph.D. Thesis, University of Nigeria, Nsukka, Nigeria. 
Ndanusa, M.S., 2010. Blue print for the development of community sports centers in Nigeria. Nigeria Solutions Center (NSC), Abuja, Nigeria.

Nevid, J.S., 2012. Psychology: Concepts and Applications. 4th Edn., Cengage Learning, Boston, Massachusetts, USA., ISBN-13: 978- 1111835491, Pages: 768.

Nwaoku, N.A., 2005. Educational Management in Nigeria-Theory and Practice. Assemblies of God Press, Abia, Nigeria,.

Ogunjini, O., 2005. Social-cultural determinants of sports participation among undergraduates in first generation Nigeria University. Ph.D. Thesis, University of Nigeria, Nsukka, Nigeria.

Orunaboka, T.T. and C.B.Ogulu, 2015. The impact of administration and sports programme implementation on the achievement of sports council at the 17th national sports Festival competition: A case study of rivers state sports council. J. Phys. Educ. Sport Manage., 6: 32-37.
Ozgider, C., 2016. Motivational factors affecting sport fans participation in UEFA Euro 2016 soccer championship. Ph.D. Thesis, Middle East Technical University, Ankara, Turkey.

Salami, A.I., 1999. An evaluation of resources allocation and utilization towards effective performance of professional division one soccer clubs in Nigeria. Ph.D. Thesis, University of Ibadan, Ibadan, Nigeria.

Siasia, S., 2011. Siasiaopens up. Soccer Stars Limited, UK.

Smith, A.C. and B. Stewart, 2007. The travelling fan: Understanding the mechanisms of sport fan consumption in a sport tourism setting. J. Sport Tourism, 12: 155-181.

Taylor, J. and S. Taylor, 2007. Psychological Approaches to Sports Injury Rehabilitation. Aspen Publisher, Maryland, USA.,.

Unokan, B., 2005. Athletics and athletes need funding to survive. The Guardian, London, UK. 